\title{
Apertura del congreso
}

\author{
Conference opening
}

Xan Rodríguez González, Esteban Fernández-Cobián, Aurea Soto Vázquez y Luis Quinteiro Fiuza

Jueves, 12 de noviembre de 2009

https://doi.org/10.17979/aarc.2009.2.1.5034

\section{XAN RODRÍGUEZ GONZÁLEZ}

Presidente de la Delegación de Ourense del COAG

Excelentísimo y Reverendísimo Señor Obispo de Ourense, Ilustrísima Concejala de Urbanismo del Concello de Ourense, autoridades presentes, estimado profesor Fernández-Cobián, estimados congresistas y público general. Les doy la bienvenida a este II Congreso Internacional de Arquitectura Religiosa Contemporánea, cuyo título «Entre el concepto y la identidad» nos reúne hoy aquí en esta pequeña — pero grande - ciudad del noroeste de la Península Ibérica, la tercera en importancia de Galicia.

Recordaba ayer con algunos de los ponentes que asistieron al primer encuentro, como iniciamos la andadura de estos congresos internacionales. De manera que -y según las palabras de nuestro Obispo- representó casi un milagro. Casi y milagro, dos palabras un tanto místicas. La primera por ser, a mi entender, uno de los identificativos del clero ouresano: casi, palabra de la que bien se podría hacer una tesis doctoral. Y la otra, milagro, porque sugiere o indica todo aquello que ocurre o se realiza aun cuando la razón a priori nos dice que es imposible. Pues bien, no sólo fue posible, sino que ese milagro cristalizó y se hizo realidad. Y actualmente está plasmado en un hermoso libro de actas.

En ese primer encuentro de arquitectura religiosa contemporánea, hace ya dos años, el ambiente que se estableció entre ponentes, comunicadores y asistentes podemos decir que fue $-\mathrm{y}$ seguimos hablando en términos religiosos- de comunión. Una comunión favorecida por nuestro Obispo, al que $-\mathrm{y}$ lo digo con todo el cariño y respeto- estamos muy agradecidos. La voluntad puesta por el anterior Presidente de la Delegación de Ourense del Colexio Oficial de Arquitectos de Galicia, José Jaime Vázquez Iglesias, en conjunción con la Diócesis, y el saber organizativo demostrado por el profesor Esteban Fernández Cobián, para el que no escatimaré bastantes elogios, cristalizaron en aquel maravilloso milagro que tan buen sabor de boca nos dejó, y que queremos repetir estos días.

¿Por qué Ourense? ¿Por qué esta diócesis? Evidentemente nos encontramos en una situación de aparente contranatura, por magnitud o relevancia, sin aparentes papeletas para resultar adjudicatarios de un evento tan singular. Sin embargo, quizá porque unos de los tres centros mas importantes del mundo antiguo y del actual posiblemente - junto con Roma y Jerusalén, Santiago de Compostela, se halla próximo a nosotros, somos el punto de paso natural —neurálgico- para acercarnos a pie desde el resto del mundo hasta el Apóstol.

Sea como fuere, todo este maravilloso milagro nos congrega hoy para hablar de los lugares, de los espacios concretos donde el hombre se dirige al encuentro con el 


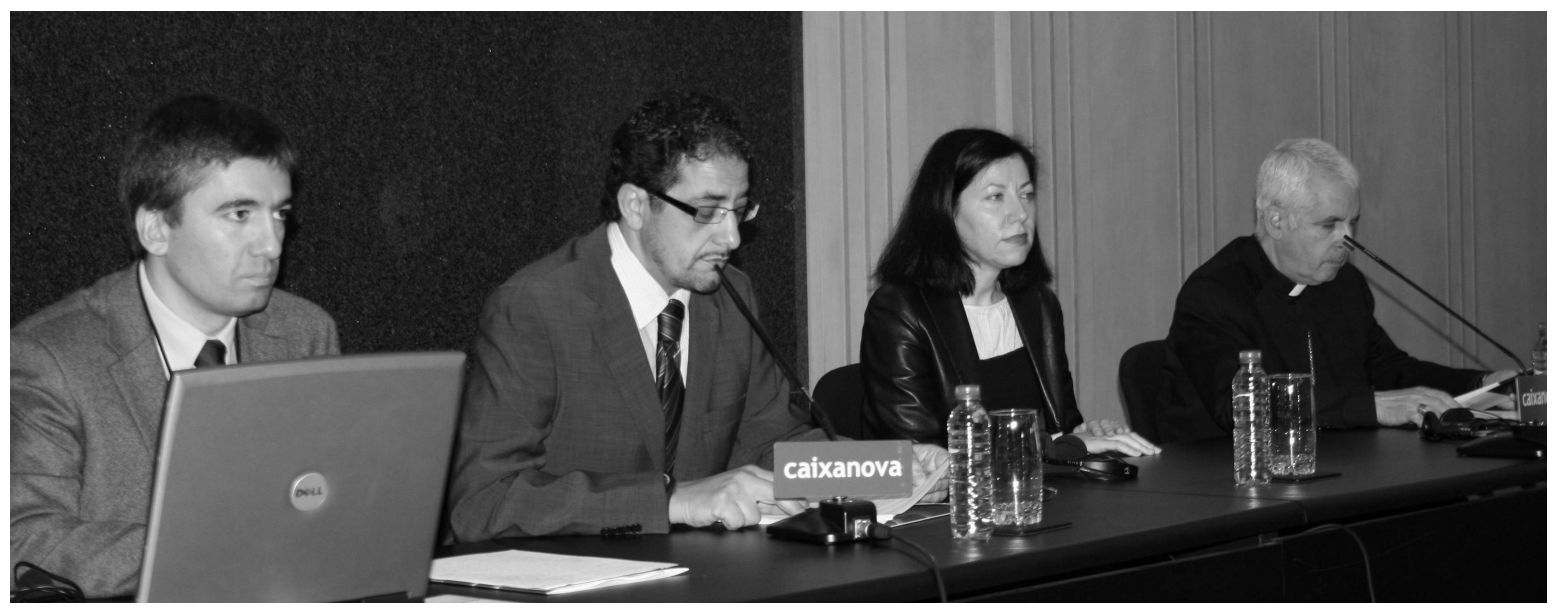

Esteban Fernández-Cobián, Xan Rodríguez González, Aurea Soto Vázquez y Luis Quinteiro Fiuza

Señor, normalmente en comunidad, aún cuando puede encontrarse solo. $\mathrm{Y}$ estos espacios, delimitados, concretados mediante la arquitectura, con la ayuda de las bellas artes - pintura, escultura, metalistería y otra muchas otras-, intentan agrupar a las personas en el camino del encuentro con su Creador a través de la atmósfera mas adecuada.

En esta edición, el Comité Científico del congreso ha centrado el debate en torno a la problemática de la transferencia de valores y el diálogo interreligioso, de forma que ello nos haga, en cierta manera, preguntarnos, entre otras cuestiones, si la nueva arquitectura religiosa se ha convertido en un lugar de experimentación formal de tipo abstracto alejado de la realidad social, o si existe algún aspecto esencial que vincule nuestra arquitectura con la tradición multisecular de la Iglesia Católica. En las intervenciones de nuestros prestigiosos ponentes y comunicadores, así como durante el debate que se abrirá en las dos mesas redondas, es posible que surja algo de luz en torno a ello. Y esta emoción compartida espero que no defraude y deje tan buen sabor de boca como la primera edición, o aún mejor.

Muchas gracias a todos por su asistencia y sean bienvenidos.

\section{ESTEBAN FERNÁNDEZ-COBIÁN Coordinador del Congreso}

En primer lugar, me gustaría darles a todos la bienvenida al II Congreso Internacional de Arquitectura Religiosa Contemporánea: «Entre el concepto y la identidad». Esperamos estar a la altura de la expectación que suscitó la primera edición celebrada hace dos años.

Mi agradecimiento a la Diócesis de Ourense, al Señor Obispo, al Vicario de Asuntos Económicos, a la Delegación de Ourense del Colexio Oficial de Arquitectos de Galicia en las personas de Xan Rodríguez, Emma Noriega, Manuel Álvarez y Mercedes Pliego, y a todas las demás personas que han hecho posible este segundo encuentro. Este segundo encuentro de personas que se reúnen alrededor de la arquitectura religiosa contemporánea. Quisiera también agradecer a los miembros del Comité Científico su magnífico trabajo en la delimitación del tema y en la selección de los participantes y comunicadores que han presentado textos para ser leídos y para su publicación en las actas.

Indudablemente - tal como se decía en el planteamiento del congreso-, la identidad del edificio de culto cristiano es uno de los problemas mas delicados que ha de afrontar la arquitectura religiosa en el arranque de este nuevo milenio. Pienso que la arquitectura religiosa contemporánea es hija de dos revoluciones: de 
la revolución arquitectónica, que se puede visualizar en el Movimiento Moderno; y de la revolución litúrgica, que también se puede ver muy claramente en el Movimiento Litúrgico. Se tata de dos peticiones de principio, de dos vueltas a los orígenes, de dos nuevas formulaciones conceptuales de un tema milenario como es la arquitectura religiosa, y que en el caso de la arquitectura cristiana, de la arquitectura católica, han dejado a los edificios de culto en una inédita situación de precariedad identitaria. Algo que no había sucedido en ningún momento de la historia. Podríamos decir que el frío concepto - lo que idealmente debe ser una iglesia - ha ahogado la vida. Pero también hay que decir que esto ha ocurrido sobre todo en Occidente.

Hoy el mundo ha cambiado. Vivimos en un mundo mestizo, un mundo lleno de migraciones, de conexiones, de oportunidades, de múltiples intercambios, de sistemas de información compartidos. La vida fluye rápido, muy rápido. Existen cruces de creencias, diálogo entre esas creencias, conflictos, y en muchas partes del mundo la religión aparece como un factor de cohesión social y de identidad comunitaria. Por eso nos podríamos preguntar: en este mundo global, ¿qué respuestas tiene la arquitectura como disciplina para estos fenómenos? ¿Qué respuestas podemos dar los arquitectos? ¿Qué experiencias —en este sentido- existen?

Pienso que un congreso es el sitio adecuado para compartir información, para exponer inquietudes, para debatir ideas. Por eso hemos invitado a ocho ponentes que, tanto desde el ámbito teórico como desde el profesional o vivencial -en el sentido mas amplio de la palabra - ilustrarán este apasionante argumento. Me gustaría agradecerles hoy su presencia entre nosotros, y especialmente a dos ponentes que han aceptado participar en este congreso a última hora para subsanar algunas bajas - siempre inevitables - que hemos tenido. La primera fue la de el profesor Giuliano Gresleri, que debido a un inesperado problema de salud no ha podido desplazarse hasta Ourense. Esta tarde tendremos entre nosotros a Glauco Gresleri, que dsarrollará un argumento muy similar al que iba a exponer su hermano Giuliano. Son compañeros cercanos, evidentemente, compañeros de estudio y de mil batallas. $Y$ en segundo lugar a Fernando Tabuenca y a Jesús Leache, dos jóvenes arquitectos que, debido a la baja repentina del profesor Josep Quetglas, han querido estar con nosotros para explicarnos una iglesia que acaban de terminar en
Pamplona, la iglesia de San Jorge, que ha sido finalista en última Bienal de Arquitectura Española.

Quisiera destacar la amplia respuesta que desde todos los rincones del mundo - desde los Estados Unidos hasta Rumanía, desde Argentina hasta Kosovo- ha tenido nuestra petición de comunicaciones breves. Es una lástima que no sea posible exponerlas todas. Ha habido comunicaciones realmente fascinantes. Esperamos que la selección que aquí se presentará $-\mathrm{y}$ que se completará posteriormente en las actas - ayude a mostrar la amplitud del problema y la inquietud que existe en la actualidad alrededor de este argumento. Agradezco a la Fundación Frate Sole, en la persona de su presidente Luigi Leoni y de su secretario Andrea Vaccari, la cesión de la exposición del IV Premio Internazionale di Architettura Sacra «Frate Sole», que esta tarde inauguraremos en El Liceo de Ourense. Finalmente, están ustedes invitados a asistir al Concierto de Música Religiosa Contemporánea que mañana tendremos en la catedral, por cortesía de la Diócesis de Ourense y del Cabildo Catedralicio.

Sin mas, les doy mi bienvenida a este congreso y les agradezco su presencia junto a nosotros.

\section{AUREA SOTO VÁZQUEZ \\ Concejala de Urbanismo del Concello de Ourense}

Buenos días a todos. En primer lugar, les traigo los saludos del Alcalde, especialmente para la gente que ha organizado estas jornadas, con su felicitación y su abrazo. Y a todos los asistentes y participantes en ellas. Como sabéis, estos días el Alcalde ha tenido algunos problemas familiares y se va incorporando paulatinamente al trabajo.

Después de estas felicitaciones a los organizadores y al Señor Obispo, solamente hacer una breve reflexión. Cuando estábamos esperando ahí fuera, el Señor Obispo y yo comentábamos la importancia que tiene la arquitectura religiosa, el espacio religioso, en toda nuestra vida. No sólo en este ámbito, pero no cabe duda de que en el ámbito de lo sagrado la arquitectura forma parte de cada una de las secuencias que a todos nos van quedando en la memoria.

Estos días me acordaba del día de Todos los Santos. De cómo esto forma parte de mi vida. En el día de Todos los Santos cada uno de nosotros vamos a ver a nuestros familiares. Y en mi caso, como soy gallega, me toca ir a una iglesia pequeñita que se encuentra en una 
parroquia de la provincia de Ourense. Siempre evoco las primeras imágenes de mi infancia allí. Sitios bellísimos, tan bien aposentados en un paisaje tan peculiar para nosotros, los gallegos; en un «outeiro» rodeado de un valle. Siempre, desde la infancia, pensaba cuántas cosas habían pasado allí: qué había pasado antes de estar esa iglesia, antes de los celtas... Porque estos lugares siempre son sitios escogidos generación tras generación, y en nuestra tierra, Galicia, como estamos tan apegados al paisaje, esto se repite muchísimo. Pues este último mes yo estaba allí con mi familia y todo el resto de las familias del lugar que veníamos de sitios diferentes, para volver a saludarnos al menos un día al año por la fiesta de Todos los Santos. Bellísima también la manera cómo se arreglan la iglesia y las tumbas, que quedan integradas en el paisaje, llenas de flores. Incluso el sonido de las campanas forma parte del paisaje gallego. Ese fue mi primer contacto en la infancia con lo sagrado.

El siguiente contacto lo recuerdo ya en Ourense. La catedral, siempre olorosa; porque para mí, está relacionada con el olor. En Galicia las catedrales huelen de manera distinta a las de Castilla. Después, recuerdo los viajes a Santiago de Compostela cuando íbamos en verano a la playa. Porque en mi infancia, yo pensaba que Santiago estaba de camino a Pontevedra. Mi madre nos hacía pasar siempre por Compostela. Y ahí mis recuerdos se funden con la historia del Camino de Santiago, que después, leyendo libros, me he dado cuenta que formaba parte de toda una comunidad, la europea, a la que pertenecemos todos.

Toda esta secuencia forma parte de mi vida. Después los viajes: la belleza deslumbrante de todos los recorridos - laicos y religiosos - en Roma. Lo apabullante de todas las ciudades italianas. La delicadeza de las iglesias anglosajonas. Saltamos en el tiempo, la belleza también a otra escala - ya mas parecida a la de mi infancia, la capilla de Carracedo, en los Peares- de Ronchamp por ejemplo, tan bien implantada en un sitio en el que no solamente es importante el espacio construido, sino todo lo que pasa alrededor. La delicadeza de Tadao Ando...

Evidentemente, lo religioso, lo sagrado, forma parte de nuestras vidas desde sus orígenes: en nuestras familias, en nuestras discusiones, en nuestra manera de entender y afrontar la vida, en nuestros conflictos, nuestras dudas, nuestro enfrentamiento con el mas allá que siempre tenemos el día de Todos los Santos, por ejemplo, cuando volvemos a saludar a los que han formado parte de nuestra vida y los que nos han acompañado tanto en ella.

Como arquitecto, también entiendo lo complejo que debe de ser formar, moldear con las manos, estos espacios cuando tienes un encargo de estas características, un encargo que yo nunca he tenido. Pero siempre me han parecido espléndidos cuando se han concluido brillantemente, como en los casos que he nombrado. Supongo que de esto se hablará en estas jornadas, como ha ocurrido en las anteriores. Y espero que sean tan interesantes las ponencias como las discusiones, aunque no haya conclusiones. Porque muchas veces en la vida no hay conclusiones. Muchas veces en la vida el propio debate es lo interesante en sí mismo. Pero estoy segura que esto será así, porque lo ha sido en los años anteriores y esperemos que lo siga siendo en los siguientes. Y agradecerles de parte del Alcalde el esfuerzo que supone organizar estas jornadas, que - lo sabemos - son muy importantes para nuestra ciudad. Una ciudad que tiene que ir cogiendo un papel de liderazgo territorial en nuestra provincia, y este tipo de eventos ayudan a reforzar esta idea.

Un abrazo del Alcalde para todos ustedes y también para el Señor Obispo, con el cual les dejo ahora mismo.

\section{LUIS QUINTEIRO FIUZA Obispo de Ourense}

Comenzamos esta mañana un importante encuentro de estudiosos de la arquitectura religiosa en esta ciudad de Ourense. El programa propuesto y la alta especialización de los participantes nos permite concebir las mejores esperanzas en lo que se refiere a una reflexión serena sobre un tema importante.

El que este II Congreso de Arquitectura Religiosa Contemporánea se celebre en Ourense puede que sea casual en su etiología, pero no debería de serlo a la hora de valorar el «de dónde» de sus reflexiones. Esta tierra - lo expresaba bellisimamente hace unos momentos la señora Concejala de Urbanismo, doña Aurea Soto- es un ámbito de asentamiento en el que, hasta el presente, sus mayores siempre le han atribuido al espacio sagrado la mas alta atención. Aquí toda la vida humana se ha configurado siempre en intima relación con los espacios sagrados. Tal vez en ello - más que en ningún otro referente - reside la irresistible atracción que nuestro 
mundo ejerce sobre todo aquél que se acerca a contemplarlo. Y nosotros nos mostramos absolutamente convencidos de que el espacio sagrado constituye el polo esencial de la identidad de esta tierra que habitamos.

Por otra parte, este entorno habitado nos ofrece un escenario infrecuente de un espacio diacrónico de identidad religiosa no perturbada en muchos siglos. Alguien, alguna vez, debería reflexionar en nuestra tierra sobre las profundas consecuencias en orden a nuestra identidad que supone el hecho de que aquí se hayan conservado pacíficamente alguno de los mas señeros monumentos paleocristianos de la Península Ibérica. Y para ilustrarles, les cuento una anécdota, un hecho de vida.

Visitando hace poco con el señor Cardenal de Sevilla, la sublime iglesia mozárabe de San Miguel de Celanova, después de contemplarla él por primera vez, quedaba verdaderamente impresionado. Y después de algún momento de reflexión me dijo: «Pensar que en Sevilla, en los tiempos de San Isidoro y San Leandro, había una de las bibliotecas mas importantes del mundo... ¡Y hoy no queda absolutamente nada!» Justamente en el tiempo en el que la capilla mozárabe de San Miguel había sido construida y que permanece hoy intacta, refulgente en su belleza y absolutamente milagrosa en su tamaño.

En cualquier caso, estoy seguro de que éste es un espléndido lugar para reflexionar sobre el concepto y la identidad del espacio sagrado, propuesta de estudio de este congreso. El espacio sagrado constituye un elemento capital de la mediación, fenómeno esencial del hecho religioso. La religión, en general, tiene muy poco que ver con los conceptos abstractos, y sí esencialmen- te con las formas sensibles. Para los cristianos, Jesucristo vive en su Iglesia como cabeza de una comunidad de personas humanas que camina por la historia, que hace historia. Los cristianos celebran juntos su fe, y van modelando sus vidas en consonancia con la dimensión comunitaria de la misma. La arquitectura busca optimizar los ámbitos donde se ha de desarrollar la vida, y así, dejando que la vida fluya del mejor modo posible, sirve de marco a la vida.

$\mathrm{La}$ arquitectura religiosa cristiana nació para acoger la vida comunitaria de la Iglesia alrededor de Cristoeucaristía, para celebrar los misterios de Cristo desde la fe. Una iglesia es un lugar sagrado donde se adora y se celebra. En ella, tanto el rito como el espacio deben «convertirse», desaparecer en cierto modo, ser transparencia ofrecida al misterio presente. Se llega así, entre otras cosas, a la consideración del rito y del templo como dones, como algo recibido, anterior a uno mismo.

Pero la arquitectura religiosa - y también la arquitectura en general - refleja conceptos y transmite ideas. La idea de autoridad o de justicia, de gozo, de fortaleza. También la idea de Dios. Y refleja a cada comunidad de creyentes y a su modo de vivir la fe. Es mas: termina configurando su identidad. Pienso que la arquitectura religiosa tiene ante sí el fantástico reto de dar forma al sentido de la vida, al sentido creyente de la vida. La belleza es la forma mas asequible al hombre de hoy para acceder al misterio de Dios. Por eso, entre otras cosas, nuestras iglesias han de ser bellas, nuestras celebraciones también necesitan ser bellas, nuestro culto ha de ser una ofrenda valiosa por parte de todos. Dios se ha hecho uno de nosotros, habita con nosotros y lo celebramos. ¡Cantemos al Señor un cántico nuevo! 